\title{
La no-forma del amor
}

\section{The No-Shape of Love}

\author{
Tatiana Aguilar-Álvarez Bay \\ Centro de Estudios Literarios \\ Instituto de Investigaciones Filológicas
}

\begin{abstract}
RESUMEN: Este ensayo se centra en el poema con que culmina La forma del agua, la más reciente obra de Guillermo del Toro. En el comentario se revisa la función del poema en la cinta, la discusión en internet acerca de la autoría de este y el carácter místico de esta breve composición. Se muestran así la coherencia entre el poema final y los rasgos plásticos y narrativos de esta historia única.
\end{abstract}

ABSTRACT: This essay focuses on the poem that culminates The Shape of Water, Guillermo del Toro's most recent work. This commentary reviews the function of the poem in the film, the internet's discussion about its authorship, and the mystical nature of this brief composition. This shows the coherence between the final poem and the plastic and narrative features of this unique story.

Palabras ClaVE: Guillermo del Toro, La forma del agua, mística, poesía erótica, mito KEYwORDS: Guillermo del Toro, The Shape of Water, mysticism, erotic poetry, myth RECIBIDO: 25 de abril de 2018 - ACEPTADO: 25 de mayo de 2018 


\section{Tatiana Aguilar-Álvarez Bay}

Centro de Estudios Literarios

Instituto de Investigaciones Filológicas

\section{La no-forma del amor}

La película La forma del agua (Del Toro 2017) culmina con un poema multicitado en varios idiomas en las redes sociales. En combinación con hermosas escenas submarinas, al principio y al final de la historia, se escucha la voz de un contador de cuentos cuyo relato, referente a un reino justo, una princesa muda y un monstruo, parece emerger del sueño. Anticipo que la "monstruosidad" avalada por Del Toro remite a la impresión de extrañeza frente al ser amado, manifiesta en la dificultad para recomponer una imagen que, como la figura en el caleidoscopio, se modifica siempre ante el ojo que la atisba. Tema que, como es sabido, ha sido recurrente en la poesía lírica. Ante esa imagen huidiza, surge el convencimiento de que el ser amado en realidad no se asemeja a nada ni a nadie, revelándose así como un ser único. En este marco, a modo de cierre de la película, aparece el poema en que se enfoca este ensayo:

Si les contara de ella, ¿qué diría? ¿Que vivieron felices para siempre? Yo creo que sí. ¿Que estaban enamorados?, ¿que permanecieron enamorados? Estoy seguro de que es verdad. Pero cuando pienso en ella - en Elisa- lo único que me viene a la mente es un poema, susurrado por alguien enamorado, hace cientos de años:

"Incapaz de percibir tu forma / te encuentro a mi alrededor. / Tu presencia llena mis ojos con tu amor / vuelve humilde mi corazón / porque estás en todas partes".

\footnotetext{
Voz en off en la última escena de la película.
} 


\title{
Ubicación del poema
}

En caso de encontrarse en una antología voluminosa, este breve poema podría pasar desapercibido; quizá no lograría atraer la atención al hojear, con algo de distracción y sin más guía que el azar, las numerosas páginas; muy probablemente seguiría olvidado en algún rincón de una librería desconocida. Sin embargo, situado como final de La forma del agua, aparece como una joya. Tras un esmerado trabajo, el paciente orfebre engasta la piedra preciosa en el espacio dispuesto previamente. La pericia consiste en elaborar el soporte en el cual puede lucir mejor la reverberación de la piedra. Tal es el efecto que consigue Guillermo del Toro al sintetizar la película en un poema. En ese momento, los protagonistas descienden al fondo del agua, al tiempo que se revela el motivo de la atracción inmediata de Elisa Esposito (Sally Hawkins) por el monstruo - un humano anfibio al que se rinde culto en la Amazonia-, a la vez que, como ocurre en El patito feo (Andersen 1843), se revela la verdadera estirpe de la protagonista. Se logra así un final sorpresivo, mientras que el agua, motivo que articula la película, cubre por completo la pantalla. El poema, "susurrado por alguien enamorado hace cientos de años", se desliza en la inmensidad líquida con la que hace perfecto juego. También es destacable el uso del verbo "susurrar", ya que concuerda con la ternura de la escena y reactualiza palabras atemporales, en el sentido de que podrían ser dichas por cualquiera en un momento de intensidad erótica semejante:

\author{
Incapaz de percibir tu forma \\ te encuentro a mi alrededor. \\ Tu presencia llena mis ojos con tu amor \\ vuelve humilde mi corazón \\ porque estás en todas partes.
}

$\mathrm{Al}$ adoptar formas diversas y por su fluir incesante, el agua ha sido siempre un símbolo de transformación y vida que la poesía recurrentemente asocia con el poder creador y el erotismo. El agua escapa a determinaciones y, por lo mismo, su presencia resulta intermitente: aparece y, en cuanto intenta asirse, queda fuera del alcance; envuelve con 
suavidad y, aunque se puede sentir, no hay manera de sujetarla, por lo que contagia la fuerza de la libertad. Por ese juego de determinación-indeterminación, la magia del agua nos deslumbra. Todos estos aspectos se pueden trasladar al multiforme amor que representa Elisa. Las palabras que anteceden al poema, antes citadas, confirman que estamos ante un final de cuento de hadas. Sin embargo, Guillermo del Toro provoca una sutil desviación de las pautas genéricas, ya que resta importancia al final feliz y al amor eterno, ubicados en segundo plano en relación con lo que de verdad se desea testificar: la cualidad líquida, envolvente, sorpresiva y libre del amor.

Si el poema apareciera al inicio de la película, muy probablemente habría pasado desapercibido - al igual que la composición incluida en una hipotética antología- . No solo porque es necesario que Elisa demuestre ser merecedora de tal homenaje, sino porque el público actual, habituado al realismo más crudo y la violencia, requiere preparación para recibir, sin un gesto de incredulidad, este final abiertamente lírico. En cambio, gracias al crescendo de emoción y al torrente seductor de las imágenes, y después de atravesar junto con la protagonista el sorprendente encuentro, la paulatina y delicada proximidad, el júbilo erótico, la angustia por la supervivencia, el terror de la separación, todo esto salpicado de ternura y humor, el poema acrecienta su fuerza persuasiva; produce el efecto de una explosión que había venido siendo contenida y a la que, finalmente, se deja libre curso. Además, con este final, se cierra el círculo entre la última escena y la del comienzo de la película, cuyas resonancias son manifiestas: ocurren debajo del agua, comparten el espacio y tiempo del mito, señalan el misterioso origen de la protagonista - la princesa muda - y aluden a la recuperación del reino justo por el que luchan Elisa y sus amigos a lo largo de la historia.

\section{Atribuciones}

Después de ver la película muchos sintieron la urgencia de conocer al autor del poema que expande, a la vez que condensa, el sentido de $L a$ forma del agua; imaginaban que bastaría copiarlo en Google y dar un clic para salir de la duda. Por mi parte, aposté por la autoría de John 
Donne (1572-1631), representante de la poesía metafísica inglesa, debido a la concepción del amor como principio infinito y eterno al que se atribuye el orden dinámico del universo. De raíz neoplatónica, dicha idea también presenta el amor como acicate de la vida, al estilo de la lírica medieval y renacentista.

Para sorpresa del público, la búsqueda resultó circular. En Google remitía a La forma del agua, sin especificar el autor que, al igual que yo, miles de espectadores estaban buscando, guiados por la pista difundida por los fans del director, quienes señalaron que Del Toro había declarado no saber con exactitud la procedencia del poema, pero que recordaba haberlo leído en un libro de poesía árabe que frecuentó antes de hacer la película. A partir de esto, llovieron en internet las suposiciones, hasta llegar a un cierto consenso sobre la autoría del poeta persa Rumi (1207-1275) - un místico sufí-, nombre que podría aparecer en el compendio mencionado por Del Toro, y que además cumple con el requisito de haber vivido hace cientos de años: "That's the general consensus right now, Rumi definitely seems like the most likely choice, but nobody online can seem to find it (and it seems like a lot of us are looking!)" (@mollywrites, 20 de enero de 2018).2 Mes y medio después, la misma jovencita de Southhampton, @mollywrites, remitió al también poeta persa Hakim Sanai (s. XII): "I found it (with some help from a friendly internet stranger) The Way To You by Hakin Sanai, there's a few differents translations" (5 de marzo de 2018). ${ }^{3}$ Finalmente se ha generalizado esta atribución, pues parece que se descubrió en los créditos de La forma del agua un agradecimiento a dicho autor. En todo caso, se mantiene la idea de que el poema corresponde a un poeta persa de tradición mística.

Cabe añadir que en las redes se ha barajado otra atribución: Himnos del amor divino de san Simeón (949-1022), al que la Iglesia ortodoxa dio el título de "Nuevo Teólogo". Este autor también fue místico y poeta. Reseño esta discusión en internet, de un lado, para mostrar la res-

\footnotetext{
2 "Ese es el consenso general por el momento, Rumi definitivamente parece ser la opción más probable, pero parece que nadie en línea puede encontrarlo (¡y parece que muchos de nosotros estamos buscando!)"

3 "Lo encontré (con ayuda de un amigable extraño de internet) El Camino A Ti por Hakim Sanai, hay algunas traducciones diferentes".
} 
puesta a la vertiente poética de la película, ya los espectadores salen del cine intrigados y conmovidos por el poema; de otro, para señalar que Del Toro recurre a un poema místico, que la gente reconoce como tal, a modo de síntesis de lo que buscó trasmitir con La forma del agua.

La forma del agua - denominada con acierto por el público "poema visual" - requirió artesanía y fe, según declaraciones de Guillermo del Toro. En efecto, la película conjunta el dominio del oficio, con la fe en la intuición, por la que el director se deja guiar sin saber el desenlace de esta apuesta; reúne la maestría técnica aunada con la frescura del aprendiz. Lo anterior no implica complicación pedante ni hermetismo. La película no va dirigida a un público entendido, sino que apela a la fascinación que el cine - la sucesión rítmica de las imágenes en la pantalla - desde su inicio despertó en los espectadores. Se confirma así que el lenguaje lírico, del que el poema final es la culminación, cuando se sabe administrar y va respaldado por la simpatía, los contrastes entre tensión y humor, la aguda inteligencia para evitar la belleza esteoreotipada, el poder de las resonancias, la coherencia entre el discurso plástico y el musical, y muchos otros recursos cuyo comentario exigiría mayor espacio, no solo atrapa la atención del gran público, sino que muestra la vigencia de los asuntos que interpelan al ser humano.

\section{Poema místico}

El carácter místico de las atribuciones mencionadas resulta revelador, ya que no se pueden negar las marcas en el poema de la ubicuidad e infinitud atribuidas al amor, así como el sentimiento de reverencia que este inspira. La proximidad del poema con la tradición mística da pie a reflexionar sobre el error de reducir a conceptos lo que no guarda proporción con la inteligencia. "Esto nunca lo entenderías. No lo entenderías, aunque lo intentaras toda la vida", espeta a su marido Zelda (Octavia Spencer), con clara conciencia de la imposibilidad de reducir a criterios convencionales la historia de su amiga Elisa.

La exactitud del artefacto que diseña Del Toro se debe, en gran medida, al cuidado minucioso, por no decir maniaco, de los detalles: en $L a$ forma del agua nada es gratuito. Por lo que no deben pasarse por alto 
dos motivos que se refuerzan mutuamente. Por una parte, la veneración de la criatura en un país ubicado en Sudamérica, obvia referencia al "salvajismo" de esta región contrapuesta a la pretendida "civilización". Por otra, la obvia intertextualidad bíblica, siempre en boca de un agente militar llamado Richard Strickland (Michael Shannon), quien ejerce la violencia hasta la tortura, y se caracteriza por su obediencia ciega, desprecio por los demás, racismo y machismo. A partir de este siniestro personaje, se articula la crítica global al American way of life, por su hipocresía al exportar un ideal democrático que la escalada bélica desmiente, por el sometimiento a la promesa publicitaria de felicidad asociada al estatus y al éxito, por la política de exclusión que en ese momento golpea a la comunidad afroamericana, entre otros muchos aspectos que podrían mencionarse.

Las citas del Antiguo Testamento muestran el sentido de ciertas situaciones, en el estilo protestante de intercalar en la vida cotidiana versículos bíblicos ${ }^{4}$. Por ejemplo, el disgusto del agente Strickland cuando descubre que Zelda se llama también Dalila, debido al recuerdo de la derrota de Sansón a manos de una mujer. En el mismo diálogo, se denomina al monstruo "afrenta", "cosa sucia" como introducción al momento, central en la película, en que Strickland alecciona a las mujeres sobre la criatura: "Puede que piensen que esa cosa parece humana. Anda en dos patas [...] Pero, somos creados a imagen y semejanza del Señor". Enseguida pregunta a Zelda si piensa que el Señor es parecido al supuesto monstruo y ella se niega a pronunciarse sobre "la apariencia el Señor". Ante lo cual Strickland afirma: "Parece un humano. Igual que yo... O incluso tú. Un poco más como yo, supongo..." Diálogo que resume el sentido de la película: la crítica a la violencia que despoja de humanidad a quien es diferente, a la paranoia frente al otro y a la explotación. En realidad, las dos cosas van juntas porque si se admite la humanidad del marginado, se tambalean las razones en que se basa el dominio.

En cuanto a la presencia de la Biblia en La forma del agua, también sobresale la proyección de La historia de Ruth (Henry Koster, 1960) en el cine Orfeón, que con su estilo fastuoso y luminosa marquesina contribuye a la atmósfera fantástica del edificio donde vive la protagonista. La devoción y fidelidad de Ruth, quien al morir su esposo decide permanecer al lado de su suegra a pesar de no compartir raza con ella, obviamente se contrapone a la manipulación de los textos bíblicos por parte del agente Strickland. 
La afición por el pensamiento positivo, materia sobre la que versa el libro (Peale 1952) al que Strickland acude cuando se ve en problemas, coincide con la lectura unilateral del Antiguo Testamento. Obturado por los prejuicios, el agente prescinde de la complejidad textual para quedarse con recetas aprendidas de memoria que no arrojan ninguna luz sobre situaciones que exigen reconsiderar el propio punto de vista. Mientras que el contacto con la criatura transforma al resto de los personajes, Strickland permanece inamovible, inerte, en parte por su incapacidad de captar el sentido de los sucesos y de las palabras. Esta impotencia se expresa en el ataque de rabia y desesperación del agente cuando Elisa lo insulta en el lenguaje de señas que, por supuesto, no comprende. La lectura unívoca de este personaje contrasta con las múltiples interpretaciones que sugiere el poema final, cuya apertura adquiere mayor fuerza por la supresión de la autoría - a mi modo de ver- deliberada. ${ }^{5}$

La vertiente utópica de La forma del agua consiste en mostrar que la gente invisible y sin voz (Elisa y Zelda se dedican a limpiar los baños de un complejo militar) logra desafiar un sistema demoledor, aun a costa de la tortura y la muerte. Al final de cuentas, todo tipo de gente comparte la convicción de que el amor, en sus diversas manifestaciones, debería regir la vida. De ahí la inspiración que trasmite la película, cuyo discurso se puede resumir así: NO admitimos el odio ni la injusticia. Aunque nos sintamos insignificantes, sin el saber ni el poder, de la mano de los demás somos capaces de resistir y de luchar por dar cabida

Como indica Mary Kay en una reseña publicada en internet, esta necesidad de mantenerse en la indeterminación se ve reforzada tanto por el desconocimiento del autor del poema, como de la exacta disposición de este: "The exact author is unknown, and so is its lineation. But isn't that interesting? It resounds without formal shape. Everyone agrees it sounds like Rumi even though he's not credited. Nonetheless, Rumi's romance poems talk about God. To everyone in the film, the Amphibian Man seems godlike. It's fitting that his poem would be formless and still make its point - and maybe the lack of the form is the point - . So much of the time, the medium is the message" (Mary Kay, "The Shape of Water. A retold fairy tale", 21 de diciembre de 2017).

"Se desconoce el autor exacto, y también su disposición. ¿Pero, no es interesante? Resuena sin una silueta formal. Todos están de acuerdo en que suena como Rumi aunque no lo acreditan. Sin embargo, los poemas eróticos de Rumi hablan de Dios. Para todos en la película, el hombre anfibio parece un ser divino. Es adecuado que su poema no tenga forma y aun así llegué a su punto $-\mathrm{y}$ tal vez la falta de forma es el punto-. Muchas veces, el medio es el mensaje". 
al amor en la vida de que participamos. En el poema resuenan todos estos motivos, por lo que produce el efecto de un final sinfónico.

$\mathrm{Al}$ repasar el argumento de la película se abren diversas lecturas del poema. A la referencia directa a Elisa, se añade la alusión mística al amor, en el sentido de que este rebasa los límites y nadie puede apropiárselo, al modo de un principio cósmico: "amor" no se reduce a una situación concreta, sino que opera a lo largo del espacio y el tiempo. En este contexto, se advierte el alcance de la cita bíblica sobre la creación del ser humano a imagen y semejanza divina. Si el amor no se reduce a ninguna forma, la reducción de la "imagen y semejanza" a una apariencia física, en la que además se incluye una jerarquía racial, resulta grotesca, rudimentaria y cruel. De acuerdo con la mística, con este tipo de "teología" se cancela el acceso a la divinidad, de la que solo se puede saber lo que no es. De ahí la sabiduría de Zelda, quien con sencillez admite que no sabría decir "cómo es la apariencia del Señor". En boca del agente Strickland la palabra "Señor" suena a jefe, en el plano castrense, mientras que Zelda la pronuncia con reverencia, en consonancia con la transformación del corazón a que alude el poema. ¿Por qué la presencia amada vuelve humilde el corazón y qué se entiende por humildad?

La pregunta dirige la atención hacia un argumento sutil de la película. Al trasladar el esquema de la mística al de las relaciones humanas, descubrimos que también en este orden el verdadero saber se traduce en desconocimiento, ya que el signo de proximidad con una persona es precisamente la conciencia de que esta no puede ser abarcada. De ahí la gratitud y sorpresa - modulaciones de la humildad - ante el amor, en la medida que este supone un don/regalo que no se debe a méritos y, mucho menos, al rendimiento en el plano económico. El amor no responde a cálculos, solo irrumpe en formas inesperadas. Así, Guillermo del Toro desmantela la trama engañosa de la supuesta "perfección", entendida como ajuste a la norma. La criatura admite sin reservas a Elisa, sin considerarla incompleta por su mudez; de igual manera, ella se abre a la peculiar hermosura de un ser inclasificable. El director apuesta todo a esta relación entre amor e imperfección, como se lee en el discurso que pronunció el 7 de enero de 2018, cuando recibió el premio a Mejor Director en los Globos de Oro: "Desde niño le he sido fiel a los monstruos. Ellos me han salvado y me han absuelto, porque creo que los 
monstruos son los santos patronos de nuestras bellas imperfecciones y representan la posibilidad de fracasar y seguir adelante" (CineVista, 10 de enero de 2018).

En los últimos meses, Guillermo del Toro recibe prácticamente todos los premios a que puede aspirar un director de cine; acumula en su cuenta de Twitter obsequios de parte de fans de La forma del agua: caricaturas, dibujos, pinturas que recrean a los personajes de la cinta; es incluido entre los cotizados juguetes coleccionables de la National Entretainment Collectibles Association (NECA), solo disponibles en el Comic-Con de 2018 de San Diego y también en la serie de los Funko Pop! con la figura de Elisa, el monstruo y el propio Del Toro. En suma, el director mexicano cubre todos los requisitos para transformarse en un ícono del cine fantástico, la animación y el cómic que, hoy en día, se difunden masivamente y alcanzan el mayor ranking; es mundialmente reconocido y se codea con figuras como Francis Coppola y Steven Spielberg, con quienes ha creado una nueva serie documental para Netflix: Five Came Back, cuya primera temporada ya está disponible en la plataforma de streaming.

Sin embargo, el aplauso unánime no debe ocultar que el fracaso y la imperfección han sido temas recurrentes en las clases magistrales, programas y entrevistas del cineasta a propósito de la cinta ganadora del Óscar, quien se ha referido a los años de preparación y realización de la cinta como una etapa turbulenta; incluso ha declarado que, en caso de no contactar con el público a través de La forma del agua, un punto de inflexión en su trayectoria, podría haberse retirado del cine. Después del horror y tensión de su obra anterior, no debe haber sido fácil dar el giro hacia una cinta inspiradora y con "final feliz", en la cual se respira humanidad y que ofrece momentos de pleno gozo: "un cuento de hadas para tiempos difíciles", como Del Toro mismo la ha descrito. Paralelamente, el director se ha deslindado del "pensamiento positivo" al que se entrega, paradójicamente, el villano de la película; señala de modo enfático que la belleza va de la mano de la imperfección y admite que, al imaginar la historia, buscó obtener un bálsamo para sanar heridas, entre las que se puede suponer se encuentra la intemperie en que vive México y, en general, el clima de odio que se extiende en el planeta. A pesar de todo, se inclina por una obra que, según él describe, 
combina el musical, la comedia, el melodrama y el thriller - géneros en principio incompatibles - . Es decir, en una temporada oscura, tanto en lo personal como en lo social, apuesta por una locura para la que dispone de escaso presupuesto. Pero él intuye la belleza que necesita y se atreve a compartirla con el gran público, con la gente de diario que también está ávida de alegría, humor, ternura y riesgo: de musical, comedia, melodrama, thriller. Todo ello exigió admitir la vulnerabilidad y el deseo de honrar el arrojo y la generosidad de la mayoría invisible. Para contagiar esperanza y entusiasmo Del Toro tuvo que descender a la hondura donde yacen el pavor, el desaliento y los fracasos. Así, el lirismo que impregna la película no tiene nada que ver con el optimismo dulzón tan extendido en la actualidad. El imperioso pulso y la rebeldía, esto es, el talante poético de La forma del agua reside en esta sutil defensa de la supuesta "debilidad" a la cual sistemáticamente nos han enseñado a ocultar y aborrecer. A este respecto, concluyo con palabras que Del Toro dirige a las y los estudiantes de la primera clase magistral que impartió en el XV Festival de Cine de Morelia: "[Al hacer una película] hablen de cosas que les duelan, que les den vergüenza, apuro, lo que sea, porque eso es su voz. Las cosas que ustedes pueden ver como defectos, son sus virtudes" (FICM 2017).

\section{Bibliografía}

FICM (2017). "Primera clase magistral: Guillermo del Toro", Youtube, 28 de octubre de 2017, <https://www.youtube.com/watch?v=Mbidtzrg_RU>, consultado por última vez el 27 de mayo de 2018.

KAY, Mary (2017). "The Shape of Water. A retold fairy tale", Everything Trying to Kill You._21 de diciembre de 2017, <http://everythingtryingtokillyou. blogspot.mx/2017/12/shape-of-water.html>, consultado por última vez el 27 de marzo de 2018.

Koster, Henry (1960), The Story of Ruth, 132 minutos, 20th Century Fox.

"La Academia de Cine Británico se pronunció con sus nominados. La Forma del Agua lidera la lista con 12 postulaciones", Cine Vista Blog. 10 de enero de 2018, <https://www.cinevistablog.com/la-academia-cine-britanico-sepronuncio-nominados-la-forma-del-agua-lidera-la-lista-12postulaciones/>, consultado por última vez el 20 de abril de 2018. 
@mollywrites_(2018a). "That's the general consensus right now, Rumi definitely seems like the most likely choice, but nobody online can seem to find it (and it seems like a lot of us are looking!)", Twitter, 20 de enero de 2018, 19:21 horas, <https://twitter.com/mollywrites_/ status/954886515259256832>, consultado por última vez el 7 de febrero de 2018.

@ mollywrites_ (2018b). "I found it (with some help from a friendly internet stranger) - The Way To You by Hakim Sanai, there's a few different translations x", Twitter, 5 de marzo de 2018, 16:19 horas, <https://twitter. com/mollywrites_/status/970785879135571968>, consultado por última vez el 7 de marzo de 2018.

Peale, Norman Vincent (1952). The Power of Positive Thinking, PrenticeHall, New York.

ToRo, Guillermo del (2017). The Shape of Water, 119 minutos, Fox Searchlight. 